\title{
Two-Stage Repair for Aortic Regurgitation Complicated by Severe Coarctation of the Thoracoabdominal Aorta due to Takayasu's Arteritis
}

\author{
Kenji Minakata, MD; Yutaka Konishi, MD; Masahiko Matsumoto, MD; \\ Michihito Nonaka, MD; Narihisa Yamada, MD
}

\begin{abstract}
Takayasu's arteritis is a rare inflammatory aortoarteritis of unknown etiology and causes stenoocclusive disease of the aorta and its branches as well as aortic regurgitation. A surgical case of Takayasu's arteritis is presented. A 56-year-old female exhibited aortic regurgitation complicated by severe coarctation of the thoracoabdominal aorta due to Takayasu's arteritis. In this case, a 2-staged repair, consisting of an axillofemoral bypass and an aortic valve replacement, was successfully performed. (Jpn Circ J 1999; 63: 412-413)
\end{abstract}

Key Words: Aortic valve replacement; Axillofemoral bypass; Takayasu's arteritis

$\mathbf{T}$ akayasu's arteritis is a granulomatous arteritis of unknown etiology involving the aorta and its branches that causes narrowing and aneurysmal formation of the aorta as well as aortic regurgitation (AR). We present a surgical case of Takayasu's arteritis, in which a 2-stage repair, consisting of an axillofemoral bypass and an aortic valve replacement (AVR), was successfully performed.

\section{Case Report}

A 56-year-old woman was admitted to hospital due to pneumonia. Chest X-ray revealed severe cardiomegaly, so the patient was referred to a cardiologist and further examination was performed.

The patient had a 30-year history of Takayasu's arteritis with AR. She had received oral corticosteroid therapy for over 20 years, but had discontinued this therapy 1 year earlier due to controlled systemic inflammation. She had for several years exhibited dyspnea, shortness of breath on effort and claudication of the lower extremities. These symptoms deteriorated following the development of pneumonia. She complained of coldness in both of her lower extremities and was classified as being in New York Heart Association class III. Chest X-ray showed severe cardiomegaly and lung congestion. The cardiothoracic ratio (CTR) was $72 \%$. After recovering from pneumonia, cardiac catheterization was performed. Aortography demonstrated severe AR (grade 4/4) with mild aortic root enlargement as well as severe diffuse stenosis of the thoracoabdominal aorta (Fig 1). The brachiocephalic artery was mildly dilated, and the left carotid and left subclavian arteries were mildly stenotic, but not occluded. The ascending

(Received November 20, 1998; revised manuscript received January 8, 1999; accepted January 25, 1999)

Department of Cardiovascular Surgery, Japanese Red Cross Society Wakayama Medical Center, Wakayama, Japan

Mailing address: Kenji Minakata, MD, Department of Cardiovascular Surgery, Japanese Red Cross Society Wakayama Medical Center, 4-20 Komatsubara-dori, Wakayama-city 640-8269, Japan. E-mail: dr-kenji@po.iijnet.or.jp aortic pressure and the infrarenal abdominal aortic pressure were $190 / 40 \mathrm{mmHg}$ and $88 / 30 \mathrm{mmHg}$, respectively. Left ventriculography showed severe diffuse hypokinesis and the ejection fraction (LVEF) was $25 \%$. End-diastolic and

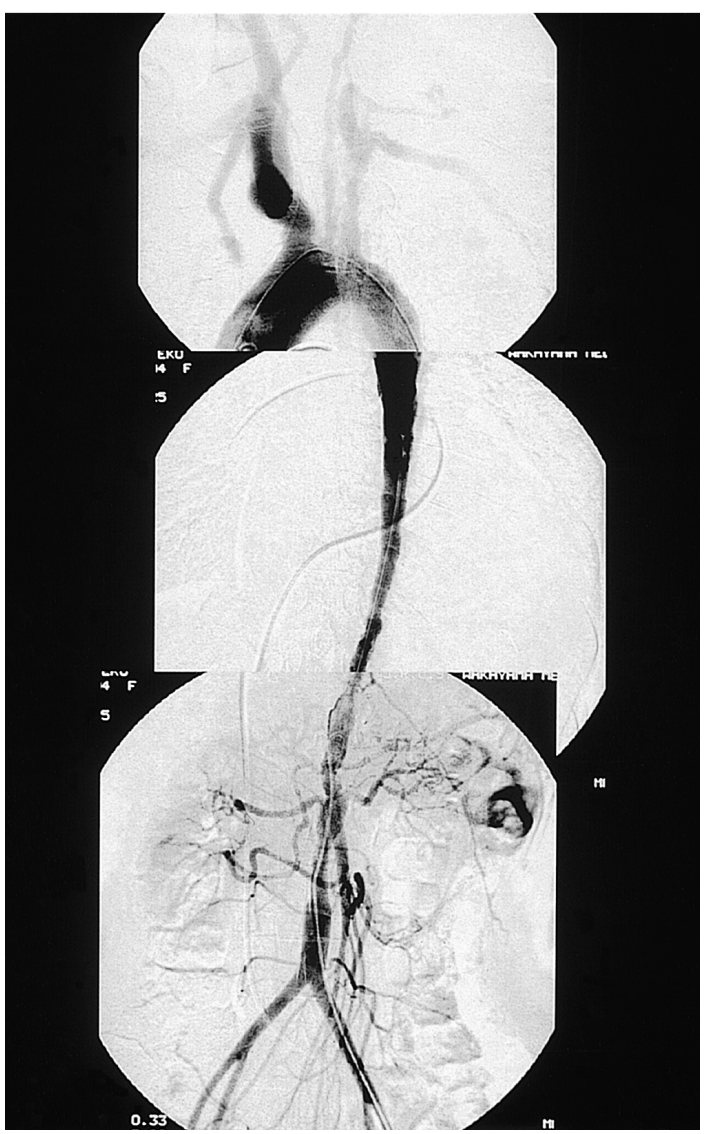

Fig 1. Aortography demonstrates marked irregular narrowing of the descending thoracic and abdominal aorta and mild dilatation of the aortic root and brachiocephalic artery. Poststenotic dilation of the abdominal aorta is not seen. The rapid tapering of the descending aorta resembles a "rat's tail" appearance. 
end-systolic volumes were $414 \mathrm{ml}$ and $310 \mathrm{ml}$, respectively. End-diastolic pressure of the left ventricle was $31 \mathrm{mmHg}$. Coronary arteries were intact. Elevated plasma renin activity $\left(6.4 \mathrm{ng} \mathrm{ml}^{-1} \mathrm{~h}^{-1}\right)$ indicated renovascular hypertension. Renal function was normal. The erythrocyte sedimentation rate and C-reactive protein were normal. Severe AR and aortic stenoocclusive disease developed into heart failure in this patient. We scheduled concomitant AVR and an aortic bypass operation, but the surgical mortality and morbidity were considered to be relatively high. Hypertension of the aortic root caused by both coarctation of the thoracoabdominal aorta and renin mediated hypertensive diathesis likely worsened the AR. Therefore, we employed a less invasive 2-stage repair technique.

During the first operation, right axillofemoral bypass grafting was carried out. The right axillary artery was mildly dilated, but the adventitia and media were not hypertrophied and the intima was not calcified. An 8-mm expanded polytetrafluoroethylene graft was anastomosed to the right axillary artery and passed through the subcutaneous tunnel. The distal end of the graft was anastomosed to the right femoral artery. After the operation, the pressure gradient between the right radial artery and the right femoral artery decreased from 110 to $40 \mathrm{mmHg}$. Congestive heart failure was well controlled medically. The plasma renin activity level decreased to $3.6 \mathrm{ng} \mathrm{ml}^{-1} \mathrm{~h}^{-1}$.

One year later, the patient was admitted for an aortic valve operation. Chest X-ray showed cardiomegaly with the CTR decreased from $72 \%$ to $58 \%$. The LVEF had improved to $65 \%$ as shown by radionuclide imaging. The patient underwent conventional AVR with a St Jude prosthetic valve (23AEC) in a standard cardiopulmonary bypass through median sternotomy. The ascending aorta was mildly dilated and the aortic wall was markedly thickened. The aortic leaflets were thin, floppy and elongated, so 2-0 Ti-Cron pledget-supported mattress sutures were employed to prevent perivalvular leakage. Histopathological examination of the aortic leaflets showed no active inflammation. The postoperative course was uneventful and the patient is doing well 6 months postoperatively. No relapse of inflammation was observed and no perivalvular leakage was detected on follow-up echocardiography.

\section{Discussion}

Nonspecific aortoarteritis, known as Takayasu's arteritis, is a rare inflammatory arteriopathic condition that predominantly affects young women and involves the aorta and its branches causing narrowing and aneurysms in vessels!,2 Bypass surgery or reconstruction of the involved vessels ${ }^{3-5}$ as well as aortic valve replacement and coronary artery bypass grafting6,7 are well documented. However, studies on concomitant aortic valve replacement and bypass surgery for the thoracoabdominal aorta are limited.

In the present patient, we performed axillofemoral bypass at the first stage of intervention to decompress the ascending aorta and increase the blood flow to visceral organs and lower extremities. We selected this extraanatomical bypass rather than total replacement of the involved aorta or aortofemoral bypass because it is less invasive and its surgical results are almost equivalent to those of aortofemoral bypass, particularly for high-risk patients? In Takayasu's aortoarteritis, arch branches are frequently involved and cause 'pulseless disease'. In such cases, axillary arteries are not indicated for arterial inflow in bypass operations. Fortunately, the right axillary artery was intact in this patient. Furthermore, poststenotic dilatation or aneurysmal formation of the abdominal aorta was not seen, therefore a simple bypass operation was sufficient.

After the first operation, cardiac function markedly improved and heart failure was well controlled medically. In the second stage, we performed conventional AVR during a standard cardiopulmonary bypass. The prior axillofemoral bypass also enabled the usual single arterial cannulation into the ascending aorta.

In conclusion, a 2-stage repair technique consisting of an axillofemoral bypass and an aortic valve replacement was safe and effective for this case of aortic regurgitation complicated by coarctation of the thoracoabdominal aorta due to Takayasu's arteritis and resulted in an early recovery with reduced morbidity.

\section{References}

1. Lupi-Herrera E, Sanchez-Torres, Marcushamer J, Mispireta J, Horwitz S, Vela JE: Takayasu's arteritis: Clinical study of 107 cases. Am Heart J 1977; 93: 94-103

2. Ishikawa K: Natural history and classification of occlusive thromboaortopathy (Takayasu's disease). Circulation 1978; 57: 27-35

3. Robbs JV, Human RR, Rajaruthnam P: Operative treatment of nonspecific aortoarteritis (Takayasu's arteritis). J Vasc Surg 1986; 3: $605-616$

4. Takagi A, Tada Y, Sato O, Miyata T: Surgical treatment for Takayasu's arteritis. J Cardiovasc Surg 1989; 30: 553-558

5. Weaver FA, Yellin AE, Campen DH, Oberg J, Foran J, Kitridou RC, et al: Surgical procedures in the management of Takayasu's arteritis. J Vasc Surg 1990; 12: 429-439

6. Suzuki A, Amano J, Tanaka H, Sakamoto T, Sunamori M: Surgical consideration of aortitis involving the aortic root. Circulation 1989; 80(Suppl I): I-222-I-232

7. Ohteki H, Itoh T, Natsuaki M, Minato N, Ueno T, Suda H, et al: Aortic valve replacement for Takayasu's arteritis. J Thorac Cardiovasc Surg 1992; 104: 482-486

8. Passman MA, Taylor LM, Moneta GL, Edwards JM, Yeager RA, McConnell DB, et al: Comparison of axillofemoral and aortofemoral bypass for aortoiliac occlusive disease. J Vasc Surg 1996; 23: $263-271$ 